NASA/TM-2008-215202

\title{
An Adaptive Instability Suppression Controls Method for Aircraft Gas Turbine Engine Combustors
}

George Kopasakis, John C. DeLaat, and Clarence T. Chang

Glenn Research Center, Cleveland, Ohio 


\section{NASA STI Program . . . in Profile}

Since its founding, NASA has been dedicated to the advancement of aeronautics and space science. The NASA Scientific and Technical Information (STI) program plays a key part in helping NASA maintain this important role.

The NASA STI Program operates under the auspices of the Agency Chief Information Officer. It collects, organizes, provides for archiving, and disseminates NASA's STI. The NASA STI program provides access to the NASA Aeronautics and Space Database and its public interface, the NASA Technical Reports Server, thus providing one of the largest collections of aeronautical and space science STI in the world. Results are published in both non-NASA channels and by NASA in the NASA STI Report Series, which includes the following report types:

- TECHNICAL PUBLICATION. Reports of completed research or a major significant phase of research that present the results of NASA programs and include extensive data or theoretical analysis. Includes compilations of significant scientific and technical data and information deemed to be of continuing reference value. NASA counterpart of peer-reviewed formal professional papers but has less stringent limitations on manuscript length and extent of graphic presentations.

- TECHNICAL MEMORANDUM. Scientific and technical findings that are preliminary or of specialized interest, e.g., quick release reports, working papers, and bibliographies that contain minimal annotation. Does not contain extensive analysis.

- CONTRACTOR REPORT. Scientific and technical findings by NASA-sponsored contractors and grantees.

- CONFERENCE PUBLICATION. Collected papers from scientific and technical conferences, symposia, seminars, or other meetings sponsored or cosponsored by NASA.

- SPECIAL PUBLICATION. Scientific, technical, or historical information from NASA programs, projects, and missions, often concerned with subjects having substantial public interest.

- TECHNICAL TRANSLATION. Englishlanguage translations of foreign scientific and technical material pertinent to NASA's mission.

Specialized services also include creating custom thesauri, building customized databases, organizing and publishing research results.

For more information about the NASA STI program, see the following:

- Access the NASA STI program home page at http://www.sti.nasa.gov

- E-mail your question via the Internet to help@ sti.nasa.gov

- Fax your question to the NASA STI Help Desk at 301-621-0134

- Telephone the NASA STI Help Desk at 301-621-0390

- Write to: NASA Center for AeroSpace Information (CASI) 7115 Standard Drive Hanover, MD 21076-1320 
NASA/TM-2008-215202

\section{An Adaptive Instability Suppression Controls Method for Aircraft Gas Turbine Engine Combustors}

George Kopasakis, John C. DeLaat, and Clarence T. Chang

Glenn Research Center, Cleveland, Ohio

National Aeronautics and

Space Administration

Glenn Research Center

Cleveland, Ohio 44135 
Level of Review: This material has been technically reviewed by technical management.

Available from

NASA Center for Aerospace Information 7115 Standard Drive

Hanover, MD 21076-1320
National Technical Information Service 5285 Port Royal Road Springfield, VA 22161

Available electronically at http://gltrs.grc.nasa.gov 


\title{
An Adaptive Instability Suppression Controls Method For Aircraft Gas Turbine Engine Combustors
}

\author{
George Kopasakis, John C. DeLaat, and Clarence T. Chang \\ National Aeronautics and Space Administration \\ Glenn Research Center \\ Cleveland, Ohio 44135
}

\begin{abstract}
An adaptive controls method for instability suppression in gas turbine engine combustors has been developed and successfully tested with a realistic aircraft engine combustor rig. This testing was part of a program that demonstrated, for the first time, successful active combustor instability control in an aircraft gas turbine engine-like environment. The controls method is called Adaptive Sliding Phasor Averaged Control. Testing of the control method has been conducted in an experimental rig with different configurations designed to simulate combustors with instabilities of about 530 and $315 \mathrm{~Hz}$. Results demonstrate the effectiveness of this method in suppressing combustor instabilities. In addition, a dramatic improvement in suppression of the instability was achieved by focusing control on the second harmonic of the instability. This is believed to be due to a phenomena discovered and reported earlier, the so called Intra-Harmonic Coupling. These results may have implications for future research in combustor instability control.
\end{abstract}

\section{Introduction}

Lean-burning, low emission combustors are being investigated for aircraft gas turbine engines. Lean combustion is shown to be advantageous for reducing Nitrogen Oxides (NOx) emissions and enhancing turbine temperature distribution and efficiency; but is also prone to thermo-acoustic instabilities. These instabilities are typically the result of the coupling of the fluctuating heat release ${ }^{1}$ (of the combustion process) with the lightly damped acoustics of the combustion chamber. The exact mechanisms involved in this coupling are not well understood and different hypotheses exist as to its precise nature. ${ }^{2}$

Combustor instability suppression presents a challenging problem for controls design due primarily to the large dead-time phase delay (of many hundreds of degrees or more) and noise in the combustion process. Besides large phase delay and noise, there are other characteristics of combustor instabilities such as amplitude modulations and net random phase walks, which could play an important role in the control design. ${ }^{2,3}$

A number of research efforts have attempted suppression of the thermo-acoustic instability through active control. ${ }^{4}$ The goal of these active control efforts was to reduce the energy concentrated at the instability frequency and to reduce the overall amplitude of the combustor pressure oscillations. Some active control concepts involved speaker actuation $^{5-11}$ and others involved fuel modulation. ${ }^{12-16}$ Fuel modulation is more applicable to aircraft gas turbine engines. Several techniques have shown some success in suppressing the frequency spectra of low frequency instabilities, with less success in suppressing the time domain pressure fluctuations. Almost all of the research in the area of active combustor instability control has made use of low-pressure, gaseous fueled combustors. One exception is the work by Barooah, et al. ${ }^{17}$ that attempted to reduce pressure oscillations with the low frequency configuration of the same liquid fueled combustor rig described later in this article. Even though the technique applied had some success in reducing the instability amplitude at the instability frequency, the instability energy was transferred to the frequency side lobes ("peak splitting"), and the overall amplitude of the combustor pressure oscillations was minimally reduced.

The Adaptive Sliding Phasor Averaged Control (ASPAC) methodology, developed by NASA and described in this article, has successfully demonstrated instability suppression for multiple combustor rig configurations. The ASPAC method was first applied to control a High Frequency Rig Configuration (HFRC) during tests conducted in 2002 at United Technologies Research Center (UTRC). These early results, presented in reference 18, demonstrated the effectiveness of the methodology in reducing the combustor pressure oscillations at the instability frequency. This testing, which included concurrent testing of an alternate NASA control method, represented the first known demonstration of actively controlled, high frequency, thermo-acoustic instabilities in a realistic aircraft gas turbine engine combustor rig (as reported in ref. 19 and described in refs. 18, 20, and 21. In June 2004, control was attempted on a Low Frequency Rig Configuration (LFRC) that was assembled at NASA GRC to further test and 
verify the control methodology. As will be shown, the LFRC exhibited a very coherent instability compared to the HFRC. (The actual engine instability, on which the HFRC design was based, exhibited instability coherence somewhere between the LFRC and the HFRC.) The ASPAC controller was also successful in suppressing this LFRC's coherent instability. Finally, due to a previously reported coupling mechanism ${ }^{18,22}$ involving the harmonics of the instability, control was then focused on the second harmonic of the instability. This approach produced superior results.

This article describes the development of the ASPAC controller and the results of testing the controller with a combustor instability rig. The article is organized as follows. A description of the combustor rig is given that includes comparisons of the instabilities of the HFRC, the LFRC, and that of a developmental aircraft gas turbine engine. This is followed by a description of the combustor instability behavioral model and the development of the control methodology. Then test results are presented for the HFRC and the LFRC, including harmonic control and its implications, followed by a hypothesis that attempts to explain the phenomena observed during testing. The article concludes with areas of future research interests.

\section{Experimental Hardware Description}

\section{A. Combustor Instability Rig}

In order to focus control development toward realistic combustion instabilities in aeronautics, a combustor rig that replicates an aircraft gas turbine engine combustor instability was designed and fabricated. ${ }^{23,24}$ This single nozzle research combustor rig was developed in partnership with Pratt \& Whitney and UTRC. A schematic of the test rig configuration is shown in figure 1 . The sample problem selected for this rig is an axial combustor instability that was observed during the development of a high-performance aircraft gas-turbine engine. The frequency of the observed instability in the developmental engine was about $525 \mathrm{~Hz}$ and the magnitude of the pressure oscillations was sufficient to cause unacceptable vibratory stresses in the turbine.

It was previously demonstrated that the combustor rig successfully replicates the axial instability observed in the engine. The single-nozzle combustor rig operates at engine pressure and temperature conditions and has many of the complexities of the actual engine combustor. These include the same air-blast, 2-stage fuel nozzle and swirler used in the engine; dilution/cooling; and an effusion-cooled liner. The fuel used in the combustor rig is JetA. A venturi pre-diffuser and dump diffuser simulate the engine compressor exit (combustor inlet) conditions. A choked nozzle at the combustor exit simulates the engine turbine stator. The nearly choked venturi and choked exit nozzle, in addition to simulating operation inside the engine, provide acoustic isolation from the rest of the facility.

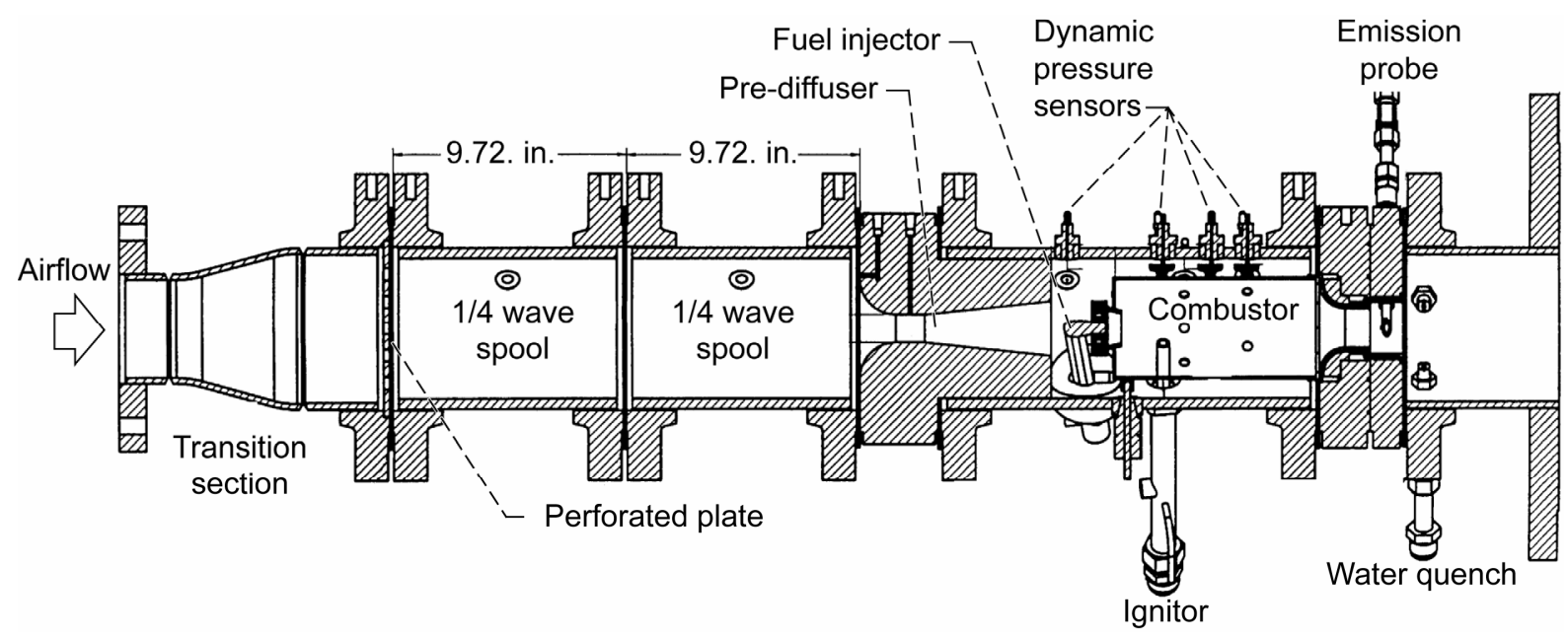

Figure 1.-Test rig configuration. 


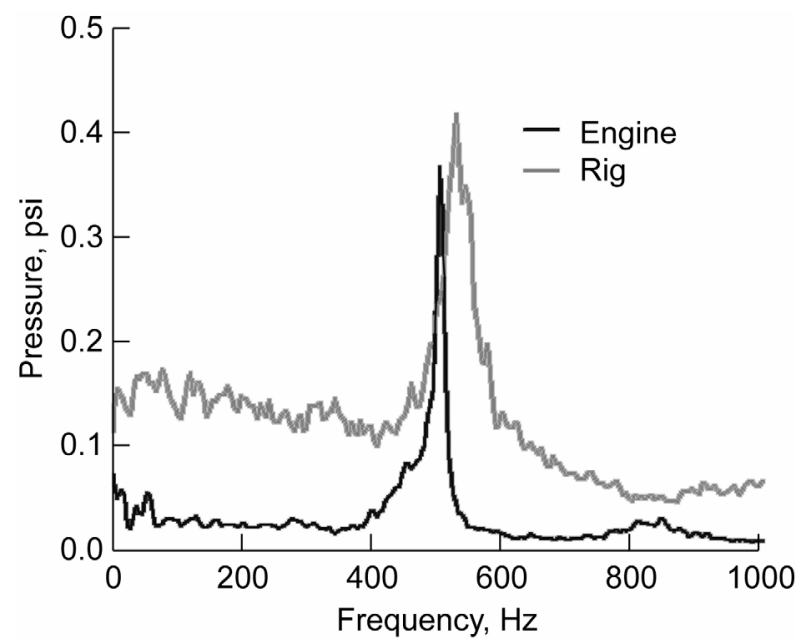

Figure 2.-Comparison of engine (mid-power) and baseline combustor rig (HFRC) pressure amplitude.
Run 423, Date 040527, Point 006
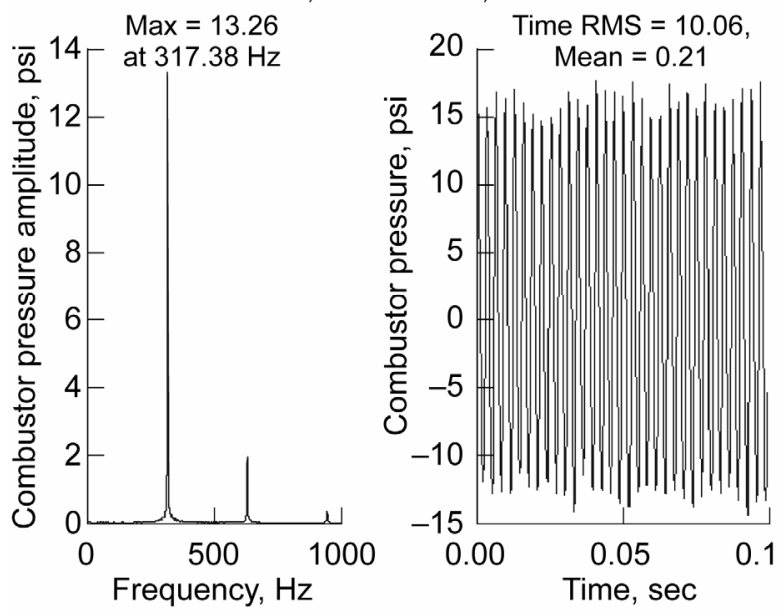

Figure 3.-Pressure amplitude spectra and time domain behavior in extended rig configuration (LFRC).

Conditions corresponding to a mid-power engine condition were chosen for evaluation $\left(\mathrm{T} 3=700{ }^{\circ} \mathrm{F}, \mathrm{P} 3=200\right.$ psia, fuel-air ratio $=0.03$ ). Water-cooled, nitrogen purged dynamic pressure transducers (PCB 12x series) were used to measure the pressure oscillations inside the combustor rig. Test results (fig. 2) established the existence of a combustor instability at about $533 \mathrm{~Hz}$ - approximately the same frequency as the developmental engine. The test rig apparatus for the $533 \mathrm{~Hz}$ HFRC is shown in figure 1. The LFRC is obtained by removing the pre-diffuser section shown in figure 1 and placing it before the two $1 / 4$ wave spool sections. This has the effect of elongating the combustor by approximately 19 in. and produces an instability at $315 \mathrm{~Hz}$.

For comparison, the pressure spectrum in the actual engine and in the single-nozzle combustor rig at comparable operating conditions for the HFRC and LFRC is shown in figures 2 and 3 respectively. This comparison shows that, in terms of instability frequency and amplitude, the HFRC closely simulates the actual engine instability. In terms of instability coherence for the fundamental (i.e. instability magnitude with respect to noise), however, the engine more closely resembles the behavior of the LFRC. These two rig configurations provide essentially two control problems. The HFRC provides a high frequency, low signal-to-noise instability problem, and the LFRC provides a lowerfrequency, high amplitude, high signal-to-noise problem.

The first experimental testing with the HFRC took place at UTRC, and the more recent control testing with the LFRC took place at NASA GRC.

\section{B. Fuel Modulation Valve}

For the open-loop fuel modulation testing and closed-loop instability control testing, a high-frequency fuel modulation valve developed by Georgia Institute of Technology was used. The valve is based on a magnetostrictive material actuator. The valve was typically located approximately 18 in. $(45.7 \mathrm{~cm})$ from the fuel injector tip. The open-loop combustor pressure response to fuel valve modulation for two different runs is shown in figure 4 . The response was somewhat nonlinear in that larger valve commands produced a disproportionately larger response in combustor pressure. However, the response of the fuel modulation system was determined empirically to be satisfactory for open-loop testing and for closed-loop instability control. The dynamics of the aforementioned fuel modulation sub-systems were not investigated further. This is, however, deemed to be an important area for future research. The fuel valve control system also had a mean flow control loop which kept the mean flow constant while the fuel flow was perturbed. This ensured that the results seen were due to fuel modulation and not to a change in fuel flow and/or fuel-air ratio. The correct operation of the mean flow control was verified during test and from posttest data. 


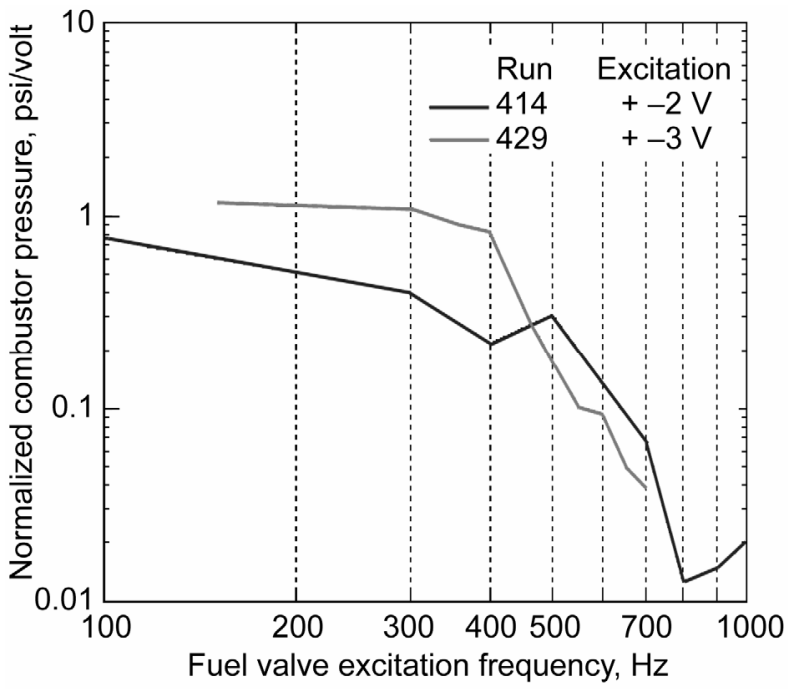

Figure 4.-Normalized combustor pressure response to perturbation of the high frequency fuel modulation valve.

\section{Combustor Instability Simulation}

The ASPAC control diagram is shown in figure 5. A reduced-order behavioral model is used to represent the combustor instability. This model consists of the flame dynamics, acoustics, and a saturation non-linearity. The instability is self-excited, that is, it requires no input via fuel injection modulation. The respective transfer functions for the flame $\left(\mathrm{G}_{\mathrm{F}}\right)$, acoustics $\left(\mathrm{G}_{\mathrm{A}}\right)$, and non-linearity $(\mathrm{NL})$ are:

$$
\begin{gathered}
G_{F}=\frac{K_{F} \omega_{F}}{s+\omega_{F}} \\
G_{A}=\frac{K_{A} \omega_{A}^{2}}{s^{2}+2 \varsigma_{A} \omega_{A}+\omega_{A}^{2}} \\
N L=\tanh (p)
\end{gathered}
$$

where $p$ is the acoustic pressure output from the transfer function in Eq. (2).

In this simulation, the flame dynamics in Eq. (1) are represented with a first order transfer function with $\omega_{F} \approx 1.1 \omega_{A}$ and a gain $K_{F}=1.2$. The acoustics transfer function dynamics in Eq. (2) correspond to an instability frequency of $\sim 533 \mathrm{~Hz}$ for the HFRC or $\sim 315 \mathrm{~Hz}$ for the LFRC. With $\varsigma_{A}=0.0707$ and $K_{A}=-0.25$, the coupled response between the flame and acoustics becomes oscillatory and unstable (growing with time). The purpose of the non-linearity (NL) is to limit the amplitude of the instability. These choices of the transfer function parameters, with the addition of any noise magnitude other than zero, allow for self sustained oscillations that closely approximate the combustor instability from time response measurements. ${ }^{4,12}$ Figure 6 shows a simulation of a self-excited instability with some injected white noise added to represent the process noise in the combustor. The response is also numerically unstable in the sense that the response depends on the damping $\varsigma_{A}$ and the sampling time $T_{s}$ $\left(T_{s}=0.0001 \mathrm{sec}\right)$, however, the results are deterministic and repeatable.

The dynamics of the fuel valve, feed lines, injector, and heat release or flame dynamics due to the fuel modulation $\left(G_{V}\right.$ in Fig. 5), have been simulated with a second order transfer function as 


$$
G_{V}=\frac{K_{V} \omega_{V}^{2}}{s^{2}+2 \varsigma_{V} \omega_{V} s+\omega_{V}^{2}}
$$

with $K_{V}=1.0$ and its natural frequency $\omega_{V}$ comfortably greater than $\omega_{A}$ so that it will not attenuate the controlled fuel modulations. $\varsigma_{V}$ is chosen to provide a damped response.

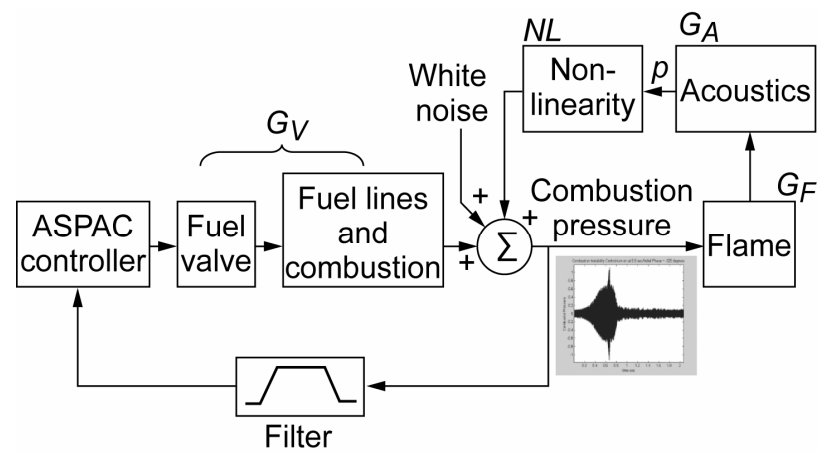

Figure 5.—Combustor instability control block diagram.
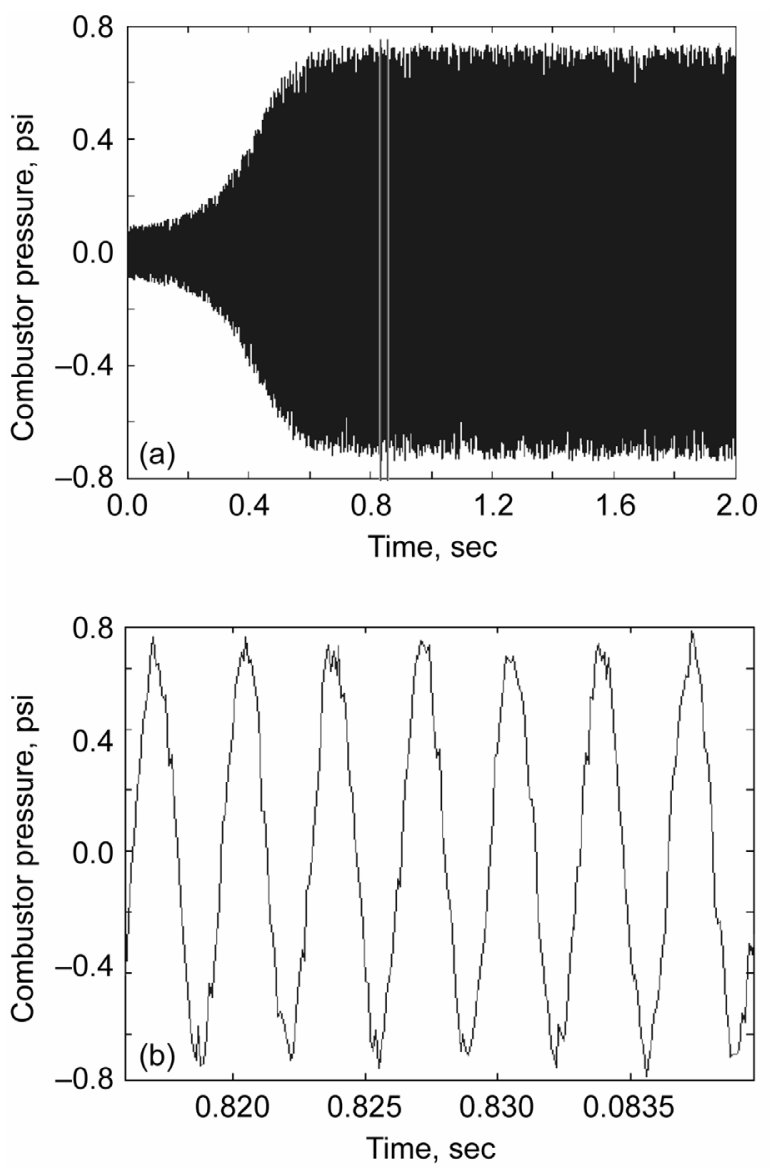

Figure 6.-(a) Self excited instability time response,

(b) Waveform of fully developed instability. 
For the filter shown in figure 5, two identical band pass filters are placed in series. The purpose of these filters is: (a) to pass the measured instability for control; and (b) when running the control with a simulated combustor, to simulate the large dead-time phase shift found in the combustion process. This phase shift amounts to approximately $760^{\circ}$ for the LFRC and is significantly larger for the HFRC. The state space model of the band pass filter is:

$$
\begin{aligned}
& \dot{x}=A x+B u \\
& y=C x
\end{aligned}
$$

with

$$
\begin{gathered}
A=1000\left[\begin{array}{cccccc}
-a 1 & 0 & 0 & a 2 & 0 & 0 \\
a 1 & -a 1 & -a 1 & 0 & a 2 & 0 \\
0 & a 1 & 0 & 0 & 0 & a 2 \\
-a 2 & 0 & 0 & 0 & 0 & 0 \\
0 & -a 2 & 0 & 0 & 0 & 0 \\
0 & 0 & -a 2 & 0 & 0 & 0
\end{array}\right] ; \\
B=\left[\begin{array}{llllll}
b & 0 & 0 & 0 & 0 & 0
\end{array}\right]^{T} \quad C=\left[\begin{array}{llllll}
0 & 0 & 1 & 0 & 0 & 0
\end{array}\right]
\end{gathered}
$$

For this simulation, $a 1_{\text {HFRC }}=0.8, a 2_{\text {HFRC }}=3.58, b_{\text {HFRC }}=800$ and $a 1_{L F R C}=0.4, a 2_{L F R C}=1.69, b_{L F R C}=400$. The Bode plot of the band pass filter for the LFRC is shown in figure 7.

\section{ASPAC Algorithm and Modifications}

The ASPAC algorithm is described in detail in references 18 and 25. In principle, the algorithm calculates a restricted control phase region in a stationary frame of reference, which is favorable for instability suppression, as shown in figure 8. First, the combustor instability pressure is sensed using a band-pass filter in order to isolate the instability frequency. The pass band of the filter is based on some a priori knowledge of the approximate instability frequency and its width covers the expected instability frequency drift within the operating range of an actual engine. The sensed pressure is phase shifted, with a phase that slides back and forth inside a restricted control region. This phase shifted pressure is used to generate a command to the fuel valve which produces a fuel modulation opposing the
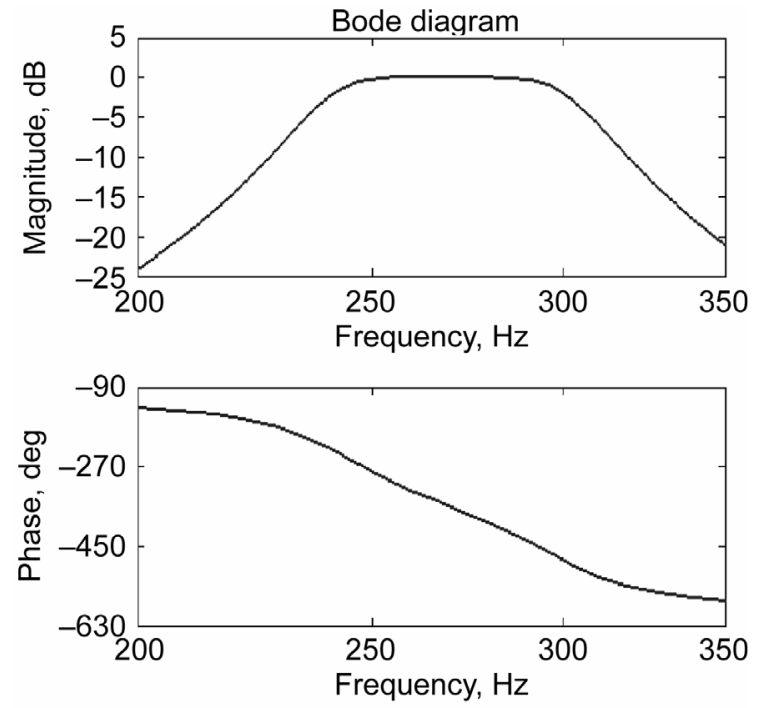

Figure 7.-Bode plot of band pass filter. 
instability pressure. The dashed line region (so called effective stability region) within the shaded area in figure 8 is the stable region in which the phase of the fuel modulation relative to the instability pressure is such that the power of the combustor pressure oscillations is reduced. The combustor pressure resulting from heat addition due to the fuel modulation, vectorially adds to the combustor pressure due to the instability to provide the overall dynamic combustor pressure.

One of the difficulties in this control problem is that the effective stability region continues to shrink as the instability is being suppressed, and eventually disappears, rendering the system unstable. This causes the stable region to open up again and the process is repeated. Combustor noise plays a major role in this process in terms of how far the instability can be suppressed. ${ }^{2}$ At higher suppression levels, the noise increasingly drives the process causing the instability phase to vary abruptly.

The pressure sensing and application of the control phase shift occurs at a rate of $10 \mathrm{KHz}$, which amounts to a phase resolution of approximately $18^{\circ}$ for the HFRC instability. The controller calculates a new phase shift at a rate of $40 \mathrm{~Hz}$. This slower control rate is due to the large dead-time phase shift, which necessitates an appropriately reduced controller bandwidth. Also, this controller optionally employs Discontinuous Exponential Gain Modulation Control $^{18,25}$ (DEGMC). In this control mode, the gain is modulated on/off with an exponential decay in order to counteract the effective proportional gain variability produced by the large dead time phase delay of the plant. DEGMC was improvised for this particular application and it is not a standardized control gain modulation technique. In addition, controller parameter adaptation ${ }^{18,22}$ is employed in order to adapt some of the key parameters of the controller.

The control design was later modified to also include harmonic control. ${ }^{22}$ The reason for this modification was evidence of the so called intra-harmonic coupling mechanism, discovered by analyzing test results. ${ }^{2,18}$ Figures 9 and 10 show this analysis. First, figure 9 shows that the instability pressure grows even though the modulated fuel command is opposing it. This instability growth persists beyond the time due to the large dead-time phase delay of the plant, and suggests another phenomenon at work. Figure 10 shows a strong coherence between the fundamental and the second harmonic of the instability in the frequency region of about 200 to $400 \mathrm{~Hz}$ suggesting a coherent energy transfer between the fundamental and the harmonic. Both these results have been produced by certain manipulations of the test data described briefly here and more fully in references 2 and 18. Figure 9 shows the combustor rig pressure and the controlled fuel modulation command for the HFRC. Both signals are filtered to show only the instability and the respective control command. The fuel control command is shown opposing the instability rather than the combustor pressure due to the fuel modulation because the latter cannot be measured separately. However, this combustor pressure will be proportional to its control command, displaced by a fixed phase. As a result, figure 9 was produced by sliding the time series of the control waveform relative to the overall combustor rig pressure so that the phases of the two signals will be opposing at the regions where the instability pressure is decreasing (this much is known). This manipulation effectively changes the control signal to an approximation of its corresponding proportional combustor pressure. Even though the controlled signal phase starts opposing the combustion pressure soon after the pressure oscillations begin to grow again, the pressure oscillations continue to grow for a while. It was suspected, based on results like figure 9, that the fundamental frequency and the harmonics are somehow coupled as inputs/outputs through an unknown mechanism. Figure 10 shows this analysis for the LFRC. One cannot compute the coherence of signals of different frequencies. Therefore, the original combustor pressure signal was band-pass filtered to isolate the fundamental instability mode. Then the original signal was also re-sampled in order to halve its frequency components. The re-sampled signal was again filtered to isolate the "fundamental mode" except this time, the "fundamental mode"

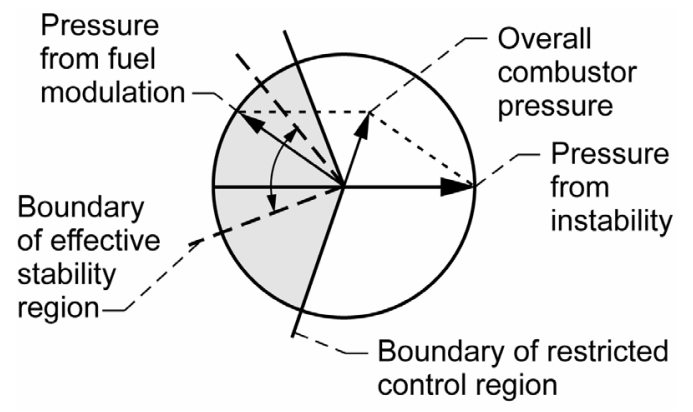

Figure 8.-ASPAC phasor diagram in a stationary frame of reference. 
is actually the original second harmonic of the instability. Finally, the coherence of these two resulting signals was computed. This effectively gives the coherence between the fundamental and the second harmonic as seen in figure 10. As shown, the coherence between the second harmonic and fundamental (in the frequency band around $300 \mathrm{~Hz}$ ) is high, around one. In figure 10, the coherences of some of the higher order harmonics are shown as well because the band-pass filters do not completely get rid of the higher order harmonics. The coherence suggested that additional suppression of the fundamental instability frequency may be possible by also simultaneously controlling the harmonics.

As a result of this analysis, the controller structure was modified by adding a $2^{\text {nd }}$ harmonic control and $3^{\text {rd }}$ harmonic control to take advantage of the intra-harmonic coupling effect. These modifications, which also include the parameter adaptation portion of the control algorithm, are shown in figure 11. The change with regard to harmonic control allows selecting the controller structure so as to focus on the fundamental and/or higher harmonics. The limitation of this control structure is the frequency that can be influenced by the fuel valve, that is, control can only be focused on the harmonic frequencies if the fuel valve has bandwidth/authority at those frequencies.

\section{Controller Test Results}

This section describes simulations and test results obtained using the ASPAC control methodology. Simulations were conducted initially to help develop the algorithm and to predict the controller behavior to the extent possible before the start of testing. Two separate tests were then conducted to validate the methodology. The first set of tests was carried out on the engine-like HFRC at UTRC, in June and September 2002. The second test was performed on the LFRC at NASA GRC, in June 2004.

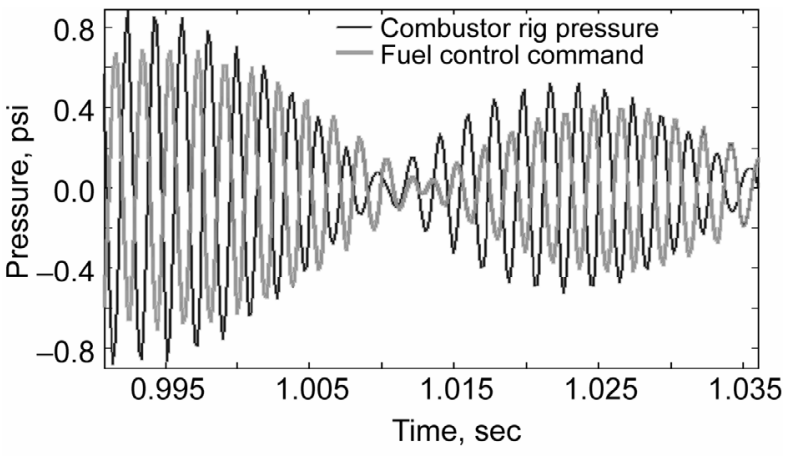

Figure 9.-Filtered combustor instability pressure versus filtered and phase shifted fuel valve control command.

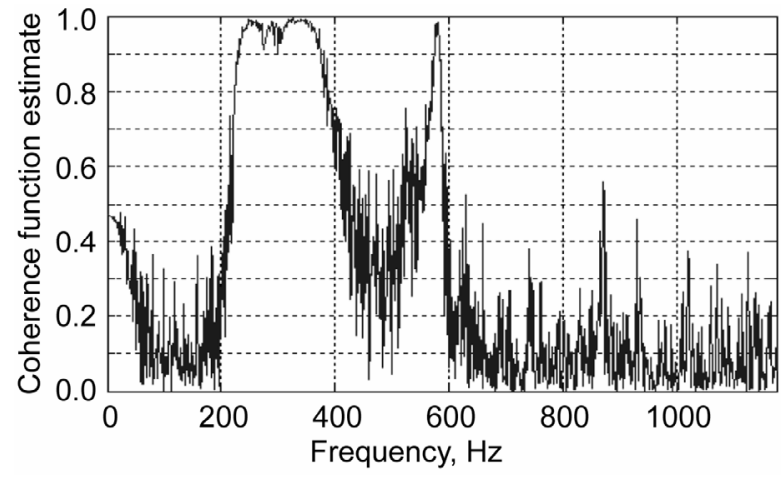

Figure 10.--Instability harmonics coherence plot.

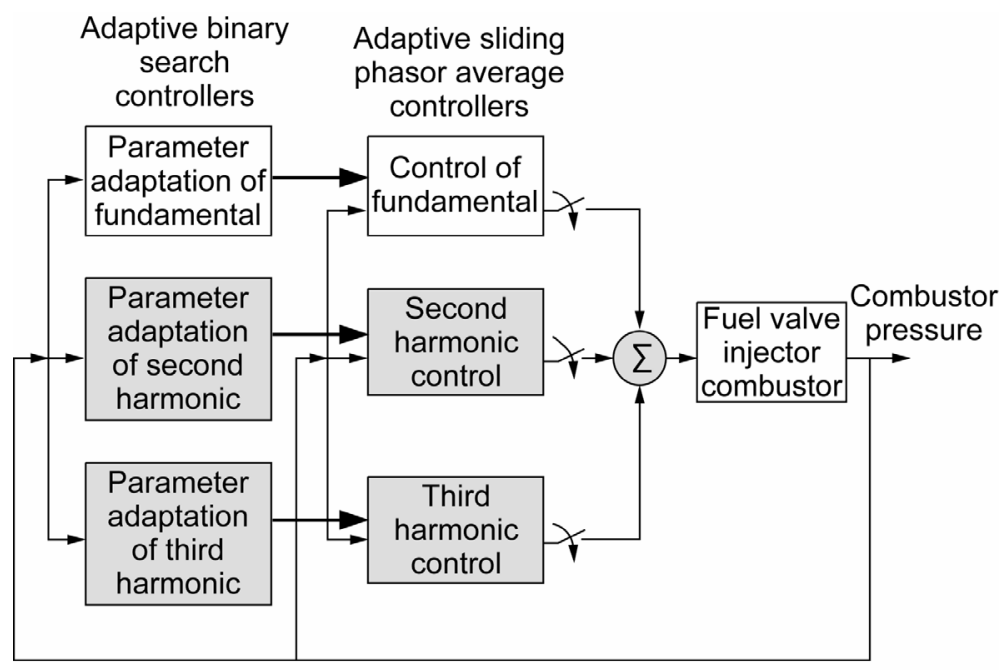

Figure 11.-ASPAC combustor instability control block diagram for harmonic control. 

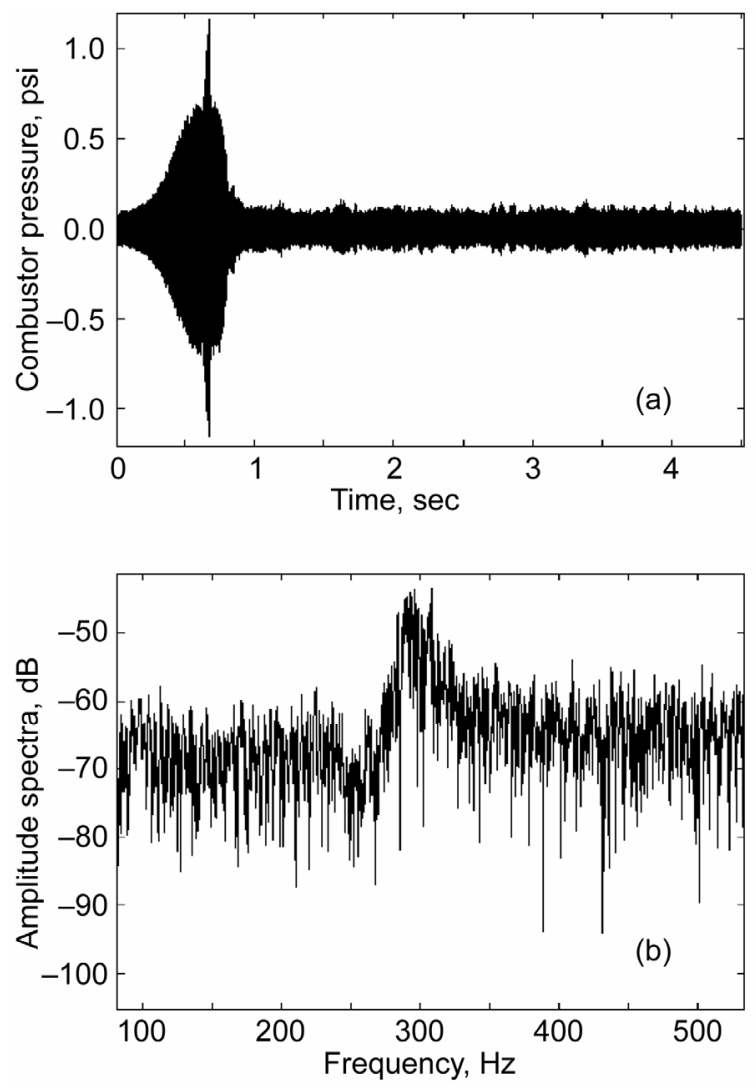

Figure 12.-Simulation of combustor instability

(a) control response and (b) power spectral density after instability suppression.

\section{A. Simulations}

Figure 12(a) shows the time response and figure 12(b) shows the power spectral density of the combustor pressure with the combustor instability simulated using Eqs. (1) to (5). The instability is allowed to grow before control is applied at about $0.6 \mathrm{sec}$. With no a priori knowledge of the phase required for suppression, the controller very briefly causes the instability to grow. The controller then quickly identifies the proper control phase to apply and suppresses the instability to reduce the instability pressure oscillations. Figure 12(b) shows the power spectral density when the controlled instability has been suppressed to about $-50 \mathrm{~dB}$ (near the noise floor for this simulation), where the uncontrolled instability magnitude is about $0.6 \mathrm{psi}$ or $-4.4 \mathrm{~dB}$. Brief control simulations were also conducted against a sectored 1-D physics based model of the combustor process ${ }^{26}$ in order to further validate the controls design.

\section{B. HFRC Test Results}

The objective of the HFRC control testing was to demonstrate control of combustor instability under conditions similar to those experienced in an actual aircraft gas turbine engine (e.g., similar in terms of the operating conditions, instability frequency, and instability amplitude, see fig. 2). As described earlier, the band pass filter used in the simulation also simulates the large phase shift experienced in the combustor instability process. However, for rig testing, the filter design was changed to remove most of the phase shift shown in figure 7. Recall that the reasons for selecting the filter design for the simulation were to help isolate the instability frequency, and also to simulate the process phase shift. As a result, a reduced phase shift filter with a 450 to $700 \mathrm{~Hz}$ pass band was selected for testing: 


$$
\begin{aligned}
& A=1000\left[\begin{array}{cccc}
-2.2627 & -1.6 & 3.51 & 0 \\
1.6 & 0 & 0 & 3.51 \\
-3.51 & 0 & 0 & 0 \\
0 & -3.51 & 0 & 0
\end{array}\right] ; \\
& B=\left[\begin{array}{llll}
1600 & 0 & 0 & 0
\end{array}\right]^{T} ; \quad C=\left[\begin{array}{llll}
0 & 1 & 0 & 0
\end{array}\right]
\end{aligned}
$$

Through simulation and experimentation, it was found that best control results are achieved with a somewhat wide band pass band filter for both the HFRC and the LFRC (i.e., about $250 \mathrm{~Hz}$ and $100 \mathrm{~Hz}$ pass band respectively).

Test results using the aforementioned control algorithm for the HFRC are shown in figure 13. Combustor pressure was sensed approximately $1 \mathrm{in}$. downstream from the fuel injector face using the previously described PCB dynamic pressure transducers. The fuel flow was modulated with the Georgia Tech fuel valve. The control algorithm was implemented on a dSpace modular control system. In both the June and September 2002 tests, the controller successfully suppressed the amplitude spectrum of the pressure oscillations at the instability frequency to near the noise floor. In terms of time domain reductions, the instability amplitude in the HFRC is small compared to the overall wideband noise $\left(\sim 1 / 7^{\text {th }}\right.$ the noise amplitude) and no apparent reductions were visible in the time domain. As seen in the upper plot of figure 13, a lower frequency coupling $(\sim 5 \mathrm{~Hz})$ existed in the combustor rig during the June 2002 testing. It was observed that occasional coupling between the combustor pressure and the facility open-loop fuel feed pressure was causing the facility fuel pressure to oscillate at this low frequency. This was remedied for the second test through filtering and tuning of the mean fuel flow controller. Figure 14 shows test results with and without DEGMC. Some noticeable improvement (approximately 25\% reduction) was observed by utilizing the DEGMC portion of the algorithm. Figure 13(b) shows the results from the second HFRC test with the fuel feed system control and DEGMC improvements.

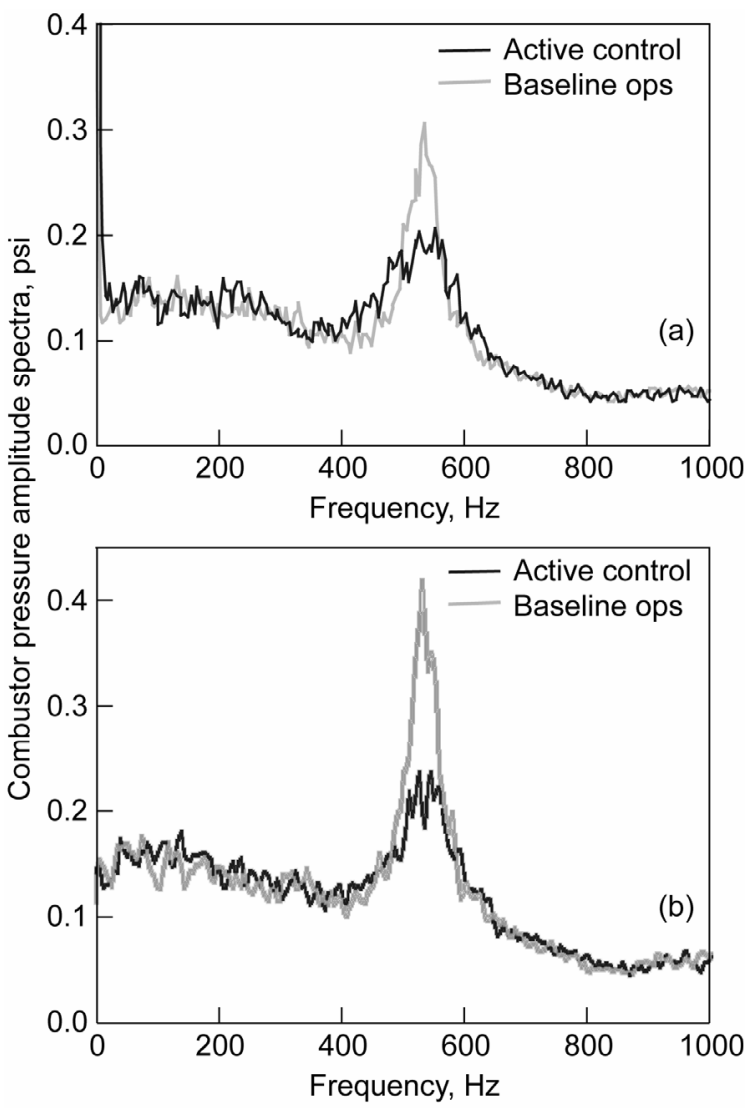

Figure 13.-Amplitude spectral density of uncontrolled versus controlled instability; (a) June and

(b) Sept. 2002 testing. 


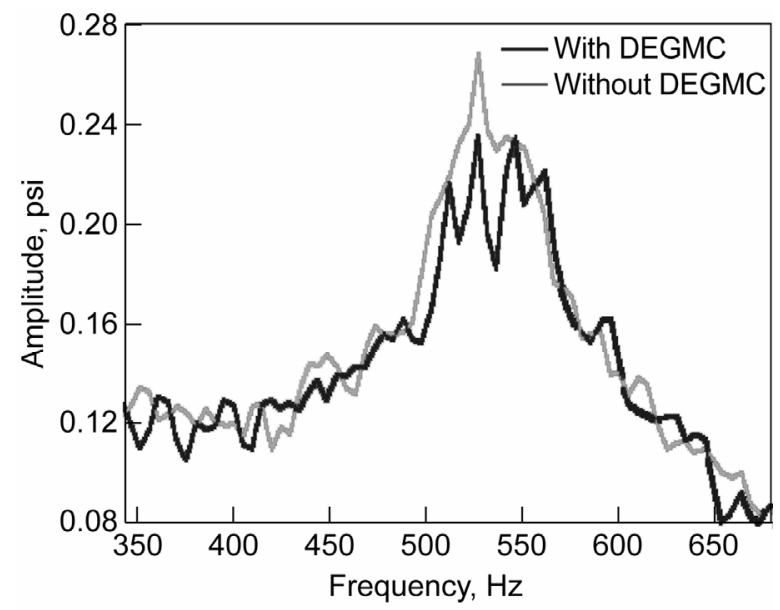

Figure 14.-Instability suppression with and without discontinuous exponential gain modulation control.

\section{LFRC Test Results}

The objective of the LFRC control testing was to demonstrate the control algorithm on a combustor rig with operating conditions similar to an actual aircraft gas turbine engine, but with an instability which is more coherent (i.e., less damped) than that of the HFRC. This more closely approximates the instability coherence of the actual engine (see figs. 2 and 3). Initially, during testing with the LFRC, control was focused on just the fundamental frequency of the instability $(\sim 315 \mathrm{~Hz})$. Through this test, good control of approximately $90 \%$ suppression of the amplitude spectrum at the instability frequency was obtained with a corresponding $35 \%$ reduction in time domain peak pressure oscillations and a 70\% reduction in RMS pressure (see fig. 15 compared to fig. 3 ). In addition to the combustor instability pressure (PLA1C1), figure 15 also shows the controller fuel valve command, in volts (REFAcmd). As shown earlier, the fuel modulation command causes a modulation pressure in the combustor of approximately $1 \mathrm{psi} / \mathrm{volt}$ up to about $350 \mathrm{~Hz}$. For this test, approximately $20 \%$ fuel pressure modulation was required for instability suppression.

During the same test run, controller action was focused on the second harmonic. The purpose of this test was to see if the instability at the fundamental frequency responds to control of the second harmonic (as discussed earlier), in order to attempt additional instability suppression. It soon became apparent that the instability fundamental not only responded to the second harmonic control, but the suppression of the fundamental was more drastic than first expected. As shown in figure 16 the peak instability pressure amplitude is $0.7 \mathrm{psi}$. Comparing this result to the uncontrolled instability of figure 3 there is $\sim 95 \%$ suppression in amplitude at the instability frequency, a $\sim 75 \%$ reduction in time domain peak pressure oscillations, and an $80 \%$ reduction in RMS pressure. The corresponding fuel valve command for this controlled combustor pressure is also shown in figure 16. From earlier frequency sweep testing, it had been observed that a 2 volt peak-to-peak fuel valve excitation at $600 \mathrm{~Hz}$ was barely registering a noticeable pressure response (i.e., pressure above the noise floor). Therefore, the relatively little control authority at the second harmonic seems to be all that was needed to suppress the instability. The band pass filter used to focus control effort on the second harmonic is wide enough to allow a small amount of effort at the fundamental. However, the higher frequency control action is what seems to provide the improved results over the fundamentalonly control. 

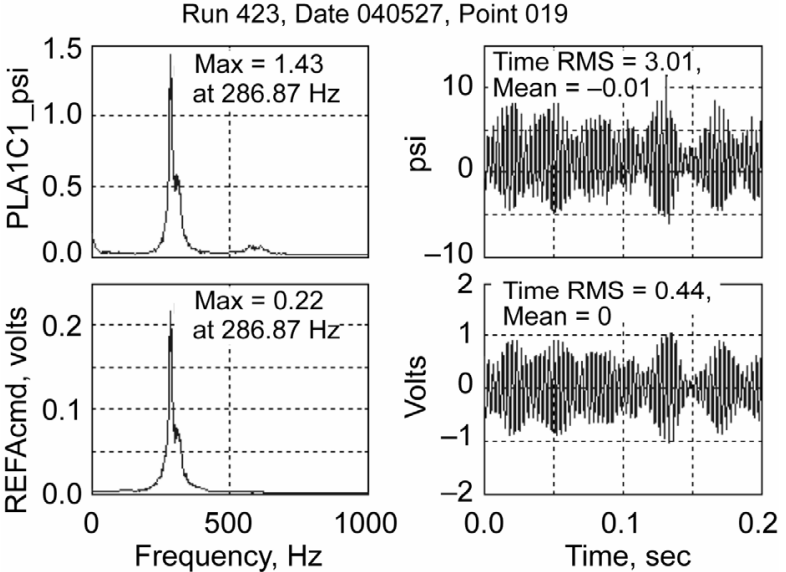

Figure 15.-Amplitude spectra and time domain of controlled instability pressure (PLA1C1_psi) and control command (REFAcmd).
Run 423, Date 040527, Point 055
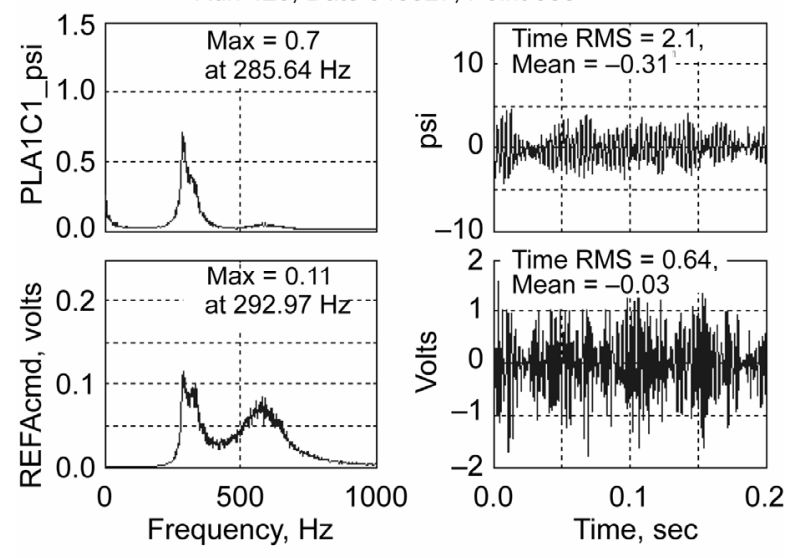

Figure 16.-Amplitude spectra and time domain of controlled instability pressure (PLA1C1_psi) and control command (REFAcmd) with harmonic control applied-Case 1.

The results from another control test also focusing on the second harmonic are shown in figure 17. For this test, parameter adaptations were enabled in the controller. These adaptations included primarily the controller gains and the parameters for the exponential gain modulation control. This result is even better in terms of the peak amplitude spectra than the result shown in figure 16 ( 0.39 versus 0.7 psi peak, $97 \%$ suppression as compared with fig. 4$)$. In both tests the second and higher harmonics of the instability have been almost completely eliminated. Some peak splitting is evident in this latter test. Depending on the particular controller design, evidence of peak splitting is more pronounced at increased levels of suppression where combustor noise becomes more dominant and net random phase walks become more abrupt. ${ }^{2}$ It is thought that this phenomenon could translate to frequency changes impacting energies at the instability side lobes. A comparison of the uncontrolled (as in fig. 3) versus the controlled instability for this last test is shown in figure 18 .

Testing focusing on the third harmonic of the instability was also carried out during the course of this test run. However, based on this testing and from frequency sweep tests, very little fuel modulation authority of the fuel valve exists at the third harmonic of $\sim 945 \mathrm{~Hz}$ (no visible modulation authority is observable from frequency sweeps tests at these high frequencies). As a result the third harmonic control testing was only able to reduce the instability by a few psi, down to about 8 psi peak pressure (results are not shown) at the instability frequency (as compared to $>13$ psi for the uncontrolled case).

The significance of second harmonic control is that better instability suppression seems to be achievable through this control, as the results presented here seem to support. The drawback is that harmonic control may require a higher fuel actuator bandwidth, and possibly a penalty on the fuel actuator life due to higher cycling rates. Both problems could possibly be mitigated by the seemingly little actuator authority needed to suppress the instability at the second harmonic, with correspondingly small magnitude dithering of the valve and small actuation rates. It could be possible that similar results may also be obtained by exercising sub-harmonic control, or control at a significantly lower frequency than the instability. The next section will offer some discussions along these lines. Interaction with other instability modes (e.g., tangential modes) would be an interesting research subject as well, but was not investigated as part of this effort. 

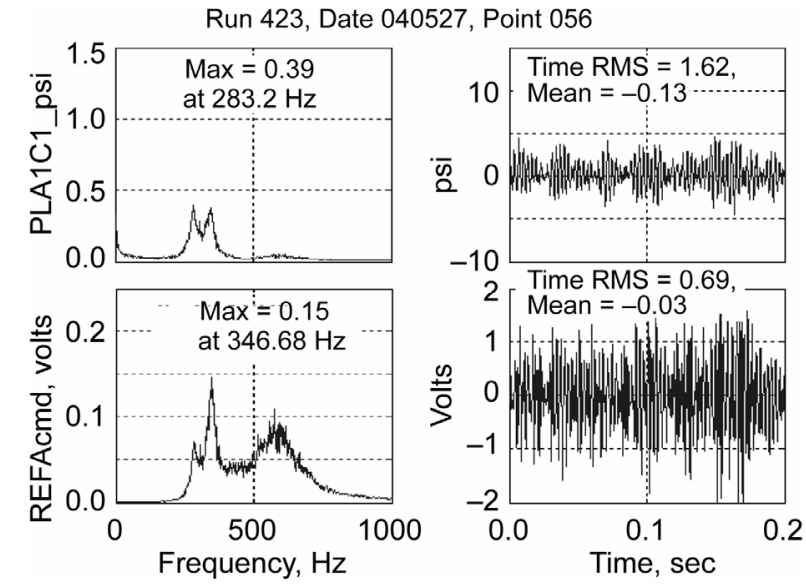

Figure 17.-Amplitude spectra and time domain of controlled instability pressure (PLA1C1_psi) and control command (REFAcmd) with harmonic control applied-Case 2.

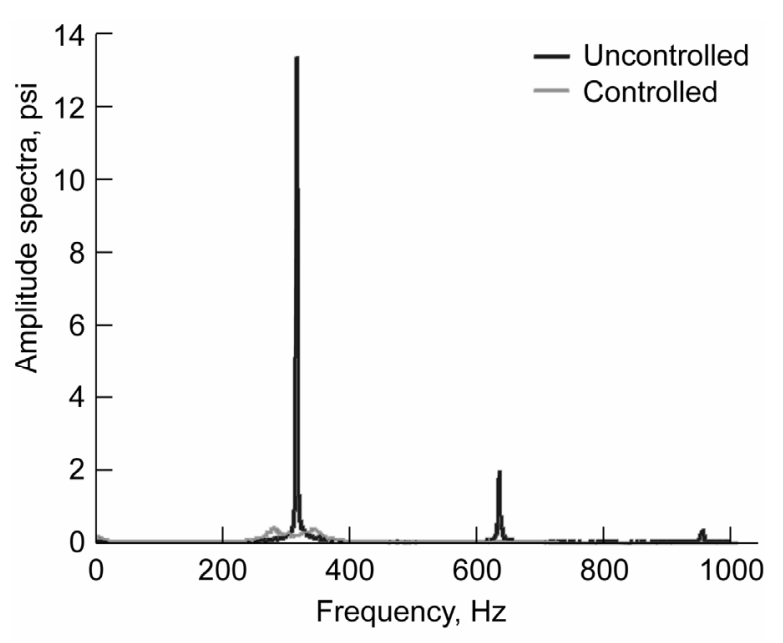

Figure 18.-Amplitude spectra of uncontrolled versus controlled instability for the LFRC.

\section{Discussion of Results}

While the primary result of the effort reported in this article is the successful suppression of combustion instability in an aircraft gas turbine engine type combustor, a discussion of how this was accomplished (focusing control effort on the second harmonic) and why this was effective seems important as well. In this section a hypothesis is offered to explain the mechanism that causes the phenomena of "Intra-Harmonic Coupling" in combustor instabilities. Also, discussed is the possible role of impedances in the root cause of combustor instabilities. These discussions are based on the previously discussed instability control test results and also on other phenomena observed during testing.

\section{A. Cause of Intra-Harmonic Coupling-Hypothesis}

In addition to closed-loop controls testing, additional test points were conducted where the combustor pressure was perturbed at various discrete frequencies, and also where semi-continuous frequency sweeps were carried out. This was done mainly to characterize the fuel valve modulation authority. However, in the process of conducting these tests, some interesting phenomena were observed. Applying a discrete modulation of 2 or 3 volts peak, at a lower frequency (in the range of $200 \mathrm{~Hz}$ ), initially, caused a barely visible response in the pressure amplitude spectra. But after about 10 minutes of running time, this modulation would rapidly grow to greater than 2 psi in the combustor pressure as if some reorganization of the combustor oscillatory waveform was taking place (fig. 19). The growth of this discrete modulation seemed to interact with the instability, reducing its peak somewhat. Further, discrete excitations at frequencies within a few $\mathrm{Hz}$ on either side of the instability frequency of approximately $315 \mathrm{~Hz}$ had an even more pronounced effect. While the peak at the excitation frequency would grow significantly, the peak at the instability frequency would be reduced dramatically (fig. 20). This latter effect can be explained by what can be called instability entrainment, whereby the system is susceptible to oscillations and will exhibit oscillatory behavior at frequencies near its resonance when excited at these frequencies; thereby increasing the system's energy at the driven frequency and at the same time reducing the energy at the resonant frequency.

Applying a discrete fuel modulation at frequencies below $200 \mathrm{~Hz}$ showed another interesting phenomena. For a $100 \mathrm{~Hz}$ modulation frequency (but not at the $155 \mathrm{~Hz}$ half-frequency of the instability), a strong interference with the instability was observed (fig. 21).

For all these open-loop modulation cases, it was observed that discrete frequency excitations seemed to create their own sub-harmonics, as well as harmonic frequencies. Overall, this combustor seemed to be very conducive to dynamic coupling between harmonics and also between discrete frequencies. 

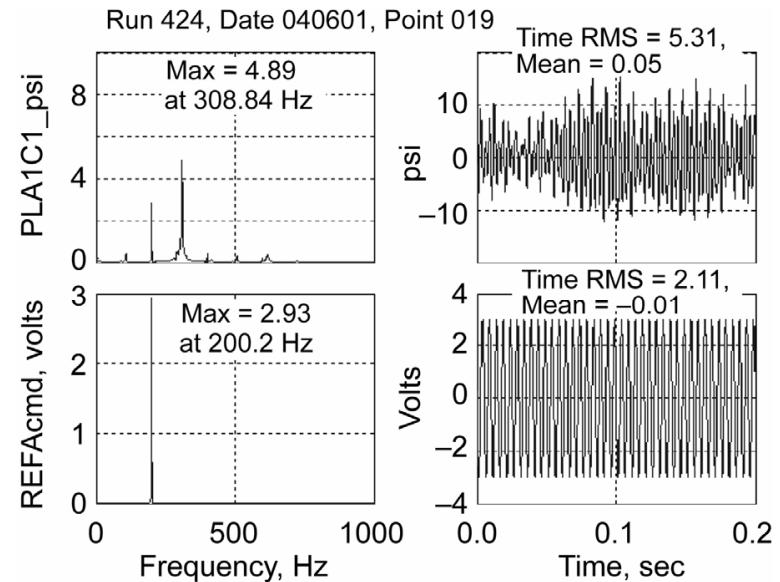

Figure 19.-Amplitude spectra and time history of combustor pressure (PLA1C1_psi) after 10 min with $200 \mathrm{~Hz}$ Fuel perturbation command applied (REFAread).

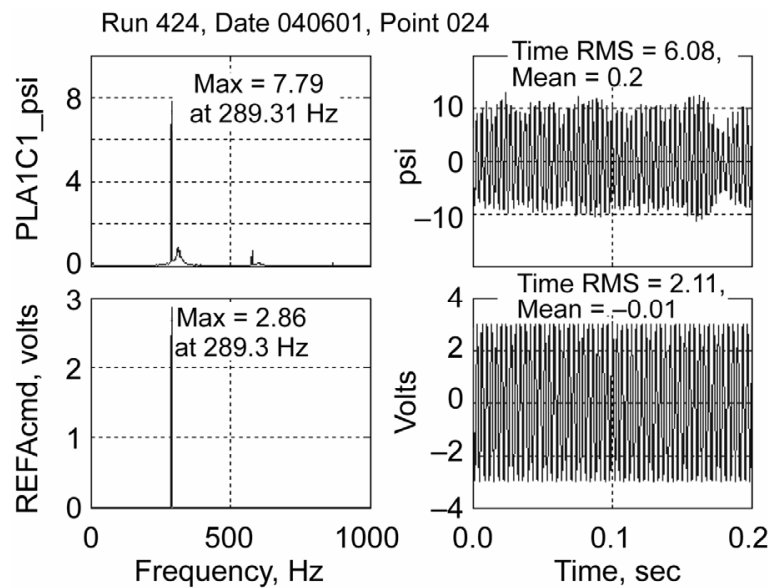

Figure 20.-Amplitude spectra and time history of combustor pressure (PLA1C1_psi) with $289 \mathrm{~Hz}$ fuel perturbation command applied (REFAread).

Run 425, Date 040602, Point 023
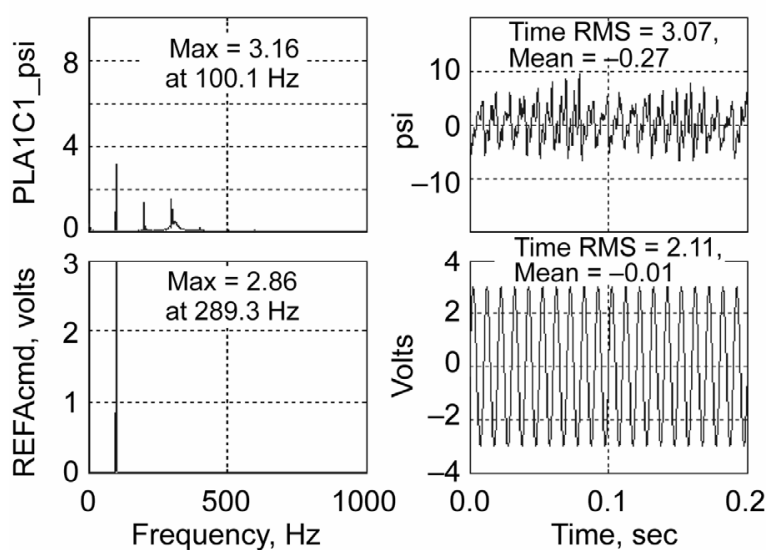

Figure 21.-Amplitude spectra and time history of combustor pressure (PLA1C1_psi) with $100 \mathrm{~Hz}$ fuel perturbation command applied (REFAread).

All these behaviors, involving couplings between harmonics and between different frequencies, could be caused by the manifestation of different dynamic processes. But it might make more sense to consider that, for the most part, the same underlying mechanism is involved and can explain all these phenomena. In general these coupling behaviors could be caused by Wave Coupling Asymmetry (WCA) as was described in some sense in reference 27 that deals with Oceanography. In terms of the combustion process, this involves the coupling of pressure waves of different frequencies. By WCA, the meaning here is that when two or more waves interfere, the interference is nonsymmetrical, causing a net suppression or amplification of the individual waves.

Let's consider for a moment energies of different frequencies, like two pressure waves, existing inside a confined domain like a combustor chamber and oriented in the same spatial direction. Even though these waves are of different frequencies, they can still interfere with one another. Such interference will manifest as cycle-by-cycle suppression or amplification of each wave, depending whether their phases are such that they promote amplification or suppression at a given instant in time. However, over the course of a combined periodic cycle (defined by the least common multiple of the two frequencies), the net change in suppression and amplification of each wave will be zero. Therefore, in an amplitude spectra density plot, the two waves will seem unaffected by each other. This can be expected to be the case, unless there is asymmetry (uneven coupling) in either the direction of suppression or amplification. 
In the case of the combustor pressure waves; when the phases of the two waves are such that amplification is supported, this action is likely opposed by damping in the form of friction (like skin friction with the walls of the chamber). This friction damping could be nonlinear, with damping increasing as the amplitude of the wave increases. On the other hand, when the phases of the two waves are such that it promotes suppression in some portion of the overall periodic cycle, the suppression will be uninhibited by damping. In such a case there will be WCA or unbalance in suppression and amplification which would favor increased suppression with time. However, as suppression increases, this asymmetry may no longer favor suppression. This is because as the wave amplitude diminishes and becomes comparable to the amplitude of the combustor noise, the noise increasingly drives the process thus preventing further suppression. At this point WCA then favors amplification. At some point a balance is reached, where the two sided WCA reaches an equilibrium point. In an amplitude spectral density plot, the two waves reach a balance between suppression and amplification, where likely the higher amplitude wave looses some net energy and the lower amplitude wave gains some net energy. This could explain what was observed in figures 19 to 21 .

The coupling of the discrete frequency excitation, which results in the growth of the discrete frequency (after some ten minutes of running time on the test rig) and the simultaneous suppression effect of the instability, cannot, however, be explained by the WCA alone. Perhaps a Minimum Energy System (MES) effect is also involved with these coupling phenomena. In such a case the relative phase of the two waveforms could also be evolving with time to cause suppression of the higher amplitude waveform and some amplification of the lower amplitude waveform, in order for the system to settle into a MES state.

If this hypothesis is correct, the question remains why controlling the second harmonic has such an immediate and major impact in suppressing the fundamental mode. The answer could be related to the periodicity of the combined wave cycle. In the case of the fundamental and its harmonics, this combined cycle has the same periodicity as the fundamental. This means that an action to suppress the fundamental can be applied as frequent as once every cycle of the fundamental. However, this would mean that applying a control action to suppress the fundamental via the second harmonic, would inevitably result in applying an equal action to amplify the fundamental, within the same cycle. But as was discussed before, coupling asymmetry due to damping, favors suppression. And because of the high frequency of control action when working with the harmonics, large levels of instability suppression are possible down near the noise floor where balance of the two sided WCA is reached. This integer multiple of periodicity between the fundamental and its harmonics in this combustor environment that favors wave interference based on the WCA, could be the cause of the intra-harmonic coupling mechanism discussed before.

The observed interaction between harmonics begs the question: Can sub-harmonic control could be used effectively to suppress the fundamental mode of the instability? In other words, the confined domain of a combustor chamber may promote coupling of energy between pressure or thermo-acoustic waves of different frequencies. But the coupling between waves with integer multiple periodicities may be more efficient, and therefore stronger. Interfering with this coupling as was done by focusing control on the second harmonic, seems to result in improved instability suppression, in fact, altogether causing the elimination of higher order harmonics which seem to behave as interdependent coherent structures. The possibility of sub-harmonic control (focusing control on frequencies that have integer harmonics at the instability fundamental) is hinted at in the result shown in figure 21. Unfortunately, testing of this hypothesis could not be investigated due to facility schedule limitations.

With a more pronounced or coherent instability where the damping is less, the level at which equilibrium in the WCA is reached, will likely be higher. Meaning that with more coherent instabilities, the WCA will still favor suppression but to a lesser degree. Based on this, the combustor noise alone (given the large dead time phase delay in the process), would not seem to be the only dominant factor in combustor instability suppression of coherent instabilities. The other limiting factor is likely the instability damping or the instability coherence.

\section{B. Possible Root Causes of Combustor Instabilities}

Some of the unexplained experimental observations concerning the open- and closed-loop response to fuel modulation bring up the more fundamental topic of the root cause of combustor instabilities. The predominant explanation in the literature is that combustor instabilities are caused by thermo-acoustic coupling, that is, coupling of the heat release with the acoustics of the combustor chamber. Based on this understanding, some experimenters have attempted to adjust the relative phase between the heat release and the acoustics by adjusting the fuel transport delay time, in order to passively suppress the instability. This approach has had mixed results, ${ }^{28,29}$ which suggests that the relative phase is not the only mechanism responsible for the presence of an instability. In reference 2 it was discussed that even though the thermo-acoustics are responsible for providing the resonance that promotes pressure 
oscillations in the combustor chamber, the exact nature of the instability, like magnitude and frequency, would seem to be the result of the fluidic impedances involved in this process (i.e., source/load type impedance interactions). Impedances play a major role in the dynamic behavior of energy transfer systems, especially in systems that are not decoupled through choking of orifices. Therefore, a complete understanding or characterization of the instability behavior can not ignore the impedances involved in this process. This is becoming an area of investigation as reported in the literature, although mainly for premixed, gaseous fueled gas turbines. ${ }^{30,31}$ Gaining a more in depth knowledge of the role that impedances play in this process, especially for liquid fueled, aircraft gas turbine engine type combustors, is of interest to the authors as a topic of future research as it may allow for more effective control designs.

The discussions in this section suggest several hypotheses concerning the nature of the mechanisms responsible for the dynamic couplings of combustor instabilities. The aim of this discussion is to promote further investigation through experiments and analysis that will either confirm or negate such hypotheses. In any case more knowledge will be gained about the behavior and control of combustor instabilities.

\section{Concluding Remarks}

This article reports on test results of an adaptive control method for suppression of combustion instabilities. Results are presented from two different test runs. The first set of runs utilized a high frequency configuration of a combustor rig which emulates an aircraft gas turbine engine combustor instability. The second set of test runs utilized a low frequency configuration of the same rig. The test results validate the effectiveness of this adaptive control method in suppressing combustor instabilities in liquid-fueled gas turbines. A certain characteristic called "Intra-Harmonic Coupling," discovered in previous analysis was exploited to produce even higher suppression levels in the control of the instability. This was accomplished by focusing control at the second harmonic of the instability. A hypothesis has been offered to explain the mechanisms involved in intra-harmonic coupling, which is attributed to a two sided wave coupling asymmetry influenced by the combined wave periodicity, and also possibly a minimum energy systems effect. Areas of interest for future research are: to apply the demonstrated phase shifting control method to advanced, low-emissions combustors; to develop actuation systems with more predictable dynamic response; and to develop a better understanding of the harmonic coupling effects and other instability mechanisms in order to support the development of even more effective control strategies (e.g., impedance-based control). Ultimately the goal of these combustor instability control efforts is to enable NOx emissions reductions through the application of advanced control approaches to ultra-low-emissions, multi-point, lean direct injection combustors.

\section{References}

1. Lefebvre, A.H., Gas Turbine Combustion, $2^{\text {nd }}$ edition, Taylor and Francis, 1999.

2. Kopasakis, G., "Systems Characterization of Combustor Instabilities with Controls Design Emphasis," AIAA 42nd Aerospace Sciences Meeting and Exhibit, Reno, NV, January 2004, NASA/TM-2004-212912, AIAA-2004-0638.

3. Lieuwen, C., Zinn, B.T., "Investigation of Cycle-to-Cycle Variability in an Unstable Gas Turbine Combustor," International Gas Turbine \& Aeroengine Congress \& Exhibition, Munich, Germany, 2000.

4. McManus, K.R., Poinsot, T., and Candel, S.M., "A Review of Active Control of Combustion Instabilities," in Progress in Energy and Combustion Science, vol. 19, issue 1, pp. 1-29, February 1993.

5. Dines, P.J., “Active Control of Flame Noise,” Ph.D. Thesis, Cambridge University, 1984.

6. Heckl, M.A., “Active Control of Noise From a Rijke Tube,” J. Sound Vib., vol. 124, no. 1, pp. 117-133.

7. Sreenivasan, K.R., Raghu, S., and Chu, B.T., "The Control of Pressure Oscillations in Combustion and Fluid Dynamical Systems," AIAA Shear Flow Conference, 1985.

8. Gleis, S., Vortmeyer, D., and Rau, W., "Experimental Investigation of the Transition From Stable to Unstable Combustion by Means of Active Instability Control," Propulsion and Energetics Panel, 75th Symposium, AGARD, pp. 22:1-6, 1990.

9. Dowling, A.P., Hooper, N., Langhorne, P.J., and Bloxsidge, G.J., “Active Control of Reheat Buzz,” AIAA-1987-433, 1987.

10. Brouwer, J., Ault, B.A., Bobrow, J.E., and Sumuelsen, G.S., "Active Control for Gas Turbine Combustors," 23rd Symposium (International) on Combustion, The Combustion Institute, Pittsburgh, PA, 1990.

11. Allgood, D., Campos-Delgado, D.U., Acharya, S., and Zhoo, K., "Acoustic Control of Thermoacoustic Instabilities Using Experimental Model-Based Controllers," Proceedings of ASME Turbo Expo, New Orleans, LA, 2001.

12. Cohen, J.M., Rey, N.M., Jacobson, C.A., and Anderson, T.J., "Active Control of Combustion Instability in a Liquid-Fueled Low-NOx Combustor," J. Eng. Gas Turbines Power, vol. 121, issue 2, 1999, pp. 281-284.

13. Hibshman, J.R., Cohen, J.M., Banaszuk, A., Anderson, T.J., and Alholm, H.A., "Active Control of Pressure Oscillations in a Liquid-Fueled Sector Combustor," International Gas Turbine \& Aeroengine Congress \& Exhibition, Indianapolis, IN, 1999. 
14. Johnson, C.E., Neumeier, Y., Nuemaier, M., Zinn, B.T., "Demonstration of Active Control of Combustion Instabilities on a Full-Scale Gas Turbine Combustor," Proceedings of ASME Turbo Expo, New Orleans, LA, 2001.

15. Murugappan, S., Park, S., Acharya, S., Annaswamy, A.M., Gutmark, E.J., Ghoniem, A.F., "Optimal Control of SwirlStabilized Combustor Using System Identification Based Model," Turbine Conference, Cesme, Turkey, 2000.

16. Murugappan, S., Acharya, S., Gutmark, E. J., and Messina, T., "Characteristics and Control of Combustion Instabilities in a Swirl-Stabilized Spray Combustor," 35th Joint Propulsion Conference and Exhibit, Los Angeles, CA, 1999.

17. Barooah, P., Anderson, T. J., and Cohen, J. M., "Active Combustion Instability Control With Spinning Valve Actuator," J. Eng. Gas Turbines Power, vol. 125, no. 4, 2003, pp. 925-932.

18. Kopasakis G., "High Frequency Adaptive Instability Suppression Controls in a Liquid-Fueled Combustor," AIAA $39^{\text {th }}$ Joint Propulsion Conference and Exhibit, Huntsville, AL, July 2003, NASA/TM-2003-211805, AIAA-2003-9581.

19. Aerospace America magazine, Monthly AIAA publication, December 2003 issue.

20. Le D.K., DeLaat J.C., Chang C.T., "Control of Thermo-Acoustics Instabilities: The Multi-Scale Extended Kalman Approach," (AIAA-2003-4934) NASA/TM-2003-212536.

21. Cohen, J., Proscia, W., and DeLaat, J., "Characterization and Control of Aeroengine Combustion Instability: Pratt \& Whitney and NASA Experience." Combustion Instabilities in Gas Turbine Engines: Operational Experience, Fundamental Mechanisms, and Modeling. Eds. Timothy Lieuwen, Vigor Yang, AIAA, Reston, VA, 2005, pp. 113-145.

22. Kopasakis, G., DeLaat J.C, Chang C.T., "Validation of an Adaptive Combustion Instability Control Method for Gas-Turbine Engines," AIAA 40 ${ }^{\text {th }}$ Joint Propulsion Conference and Exhibit, Fort Lauderdale, FL, July 2004, NASA/TM-2004-213198, AIAA-2004-4028.

23. Cohen, J.M., et al. "Experimental Replication of an Aeroengine Combustion Instability," NASA/TM-2000-210250, 2000.

24. DeLaat, J.C., Breisacher, K.J., Saus, J.R., Paxson, D.E., "Active Combustion Control for Aircraft Gas Turbine Engines," NASA/TM-2000-210346 (AIAA-2000-3500), 2000.

25. Kopasakis, G., DeLaat, J.C., "Adaptive Instability Suppression Controls in a Liquid-Fueled Combustor," AIAA $38^{\text {th }}$ Joint Propulsion Conference and Exhibit, Indianapolis, IN, July 2002, NASA/TM-2002-211805, AIAA-2002-4075.

26. Paxson, D.E., “A Sectored One-Dimensional Model For Simulating Combustion Instabilities in Premix Combustors,” AIAA $38^{\text {th }}$ Aerospace Sciences Meeting and Exhibition, Rene, NV, January 2000. NASA/TM-1999-209771, AIAA-2000-0313.

27. Shuvalov, V.V., "Mechanisms of Tsunami Generation by Impacts," Institute for Dynamics of Geospheres RAS, Leninsky pr. 38-1, 119334 Moscow, Russia.

28. Straub, D.L., Richards, G.A., "Effect of Fuel Nozzle Configuration on Premix Combustion Dynamics," International Gas Turbine \& Aeroengine Congress \& Exhibition, Stockholm, Sweden, 1996, ASME 98-GT-492.

29. Lee J.L., Kim K., Santavicca D.A., "A Study of the Role of Equivalence Ratio Fluctuations During Unstable Combustion in a Lean Premixed Combustor," AIAA 39 ${ }^{\text {th }}$ Joint Propulsion Conference and Exhibit, Huntsville, AL, July 2002, AIAA$2003-4015$

30. Richards, G., Straub, D., “Control of Combustion Dynamics Using Fuel System Impedance,” ASME Turbo Expo 2003, Atlanta, GA, June 2003, GT2003-38521.

31. Richards, G.A., Robey, E.H., "Effect of Fuel System Impedance Mismatch on Combustion Dynamics," J. Eng. Gas Turbines Power, vol. 130, issue 1, 2008. 


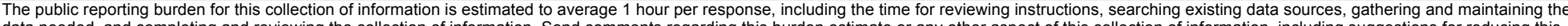

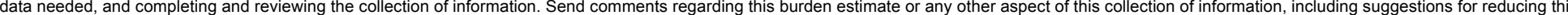

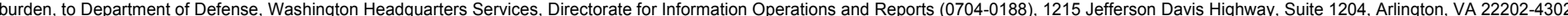

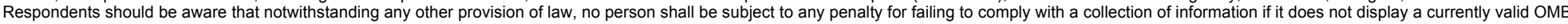
control number.

PLEASE DO NOT RETURN YOUR FORM TO THE ABOVE ADDRESS.

\section{REPORT DATE (DD-MM-YYYY) \\ 2. REPORT TYPE \\ 3. DATES COVERED (From - To)}

01-05-2008

Technical Memorandum

\section{TITLE AND SUBTITLE}

An Adaptive Instability Suppression Controls Method for Aircraft Gas Turbine Engine

Combustors

5a. CONTRACT NUMBER

5b. GRANT NUMBER

5c. PROGRAM ELEMENT NUMBER

\section{AUTHOR(S)}

Kopasakis, George; DeLaat, John, C.; Chang, Clarence, T.

\section{5d. PROJECT NUMBER}

5e. TASK NUMBER

5f. WORK UNIT NUMBER

WBS 984754.02.07.03.19.04

8. PERFORMING ORGANIZATION

REPORT NUMBER

E-16414-1

National Aeronautics and Space Administration

John H. Glenn Research Center at Lewis Field

Cleveland, Ohio 44135-3191

\section{SPONSORING/MONITORING AGENCY NAME(S) AND ADDRESS(ES)}

National Aeronautics and Space Administration

Washington, DC 20546-0001

10. SPONSORING/MONITORS
ACRONYM(S)
NASA
11. SPONSORING/MONITORING
REPORT NUMBER
NASA/TM-2008-215202

\section{DISTRIBUTION/AVAILABILITY STATEMENT}

Unclassified-Unlimited

Subject Categories: 01, 07, and 05

Available electronically at http://gltrs.grc.nasa.gov

This publication is available from the NASA Center for AeroSpace Information, 301-621-0390

\section{SUPPLEMENTARY NOTES}

Submitted to AIAA Journal of Power and Propulsion.

\section{ABSTRACT}

An adaptive controls method for instability suppression in gas turbine engine combustors has been developed and successfully tested with a realistic aircraft engine combustor rig. This testing was part of a program that demonstrated, for the first time, successful active combustor instability control in an aircraft gas turbine engine-like environment. The controls method is called Adaptive Sliding Phasor Averaged Control. Testing of the control method has been conducted in an experimental rig with different configurations designed to simulate combustors with instabilities of about 530 and $315 \mathrm{~Hz}$. Results demonstrate the effectiveness of this method in suppressing combustor instabilities. In addition, a dramatic improvement in suppression of the instability was achieved by focusing control on the second harmonic of the instability. This is believed to be due to a phenomena discovered and reported earlier, the so called Intra-Harmonic Coupling. These results may have implications for future research in combustor instability control.

\section{SUBJECT TERMS}

Combustion control; Low emissions control; Combustor instability; Active combustor control

\begin{tabular}{|c|c|c|c|}
\hline \multicolumn{3}{|c|}{ 16. SECURITY CLASSIFICATION OF: } & \multirow{2}{*}{$\begin{array}{l}\text { 17. LIMITATION OF } \\
\text { ABSTRACT } \\
\text { UU }\end{array}$} \\
\hline $\begin{array}{l}\text { a. REPORT } \\
\text { U }\end{array}$ & $\begin{array}{l}\text { b. ABSTRACT } \\
\mathrm{U}\end{array}$ & $\begin{array}{l}\text { c. THIS } \\
\text { PAGE } \\
\text { U }\end{array}$ & \\
\hline
\end{tabular}

18. NUMBER
OF
PAGES
23

\section{9a. NAME OF RESPONSIBLE PERSON STI Help Desk (email:help@ sti.nasa.gov) 19b. TELEPHONE NUMBER (include area code) 301-621-0390}



